\title{
Mathematical modeling in thermomechanics of electroconductive bodies under the action of the pulsed electromagnetic fields with modulation of amplitude
}

\author{
Hachkevych O. ${ }^{1,2}$, Musij R. ${ }^{3}$ \\ ${ }^{1}$ Pidstryhach Institute for Applied Problems of Mechanics and Mathematics \\ National Academy of Sciences of Ukraine, \\ 3-b Naukova Str., 79060, Lviv, Ukraine \\ ${ }^{2}$ Opole University of Tecnnology, 76 Prószkowska Str., Opole, 45-758, Poland \\ ${ }^{3}$ Lviv Polytechnic National University, \\ 12 S. Bandera Str., 79013, Lviv, Ukraine
}

(Received 2 May 2019; Accepted 1 June 2019)

\begin{abstract}
A mathematical model of description and a method for determining the thermostressed state of non-ferromagnetic electroconductive bodies under the influence of external unsteady electromagnetic fields of pulsed type are proposed. Such fields have the character of a regime with amplitude modulation under the action of pulse modulated signal and are widely used in technologies of magnetic pulsed processing electroconductive materials. This model is the development of well-known models for quasi-steady and pulsed electromagnetic fields. As an example, the results of investigation of the thermomechanical behavior of solid and hollow cylinders under the influence of electromagnetic pulse are given.
\end{abstract}

Keywords: mathematical model, thermomechanics, non-ferromagnetic conductive body, hollow and solid cylinders, electromagnetic pulse.

2000 MSC: $74 \mathrm{H} 10$

UDC: 539.3

DOI: $10.23939 / \mathrm{mmc} 2019.01 .030$

\section{Introduction}

Elements of the construction of modern technology, both in the manufacture and operation, are under conditions of multifactor loading, often among them are pulsed electromagnetic ones. Such loadings are widely used in technologies of proceeding of machine parts and mechanisms, in systems and devices for de-icing on airplanes and ships, for cleaning pipelines of complex shape [1-3] and so on. The functional purpose of the aforementioned technical systems and devices in which the action of the pulsed electromagnetic fields (EMF) is used is related to the creation of temperature fields and dynamic stresses (mechanical oscillations) in the corresponding elements of structures (when unwanted alien laminations or internal stresses are removed) without disturbing the carrier capacity of these elements.

The main source of creation of the pulsed EMF in the above-mentioned devices are technical means that operate according to the principle of discharge of a capacitor system onto a solenoid [4-8]. The pulsed EMF can also be created by generators of high-frequency electromagnetic oscillations. The change in time of such pulsed EMFs has the character of a regime with amplitude modulation $[1,3,5]$. This class of the pulsed EMF can be widely used in connection with the ability to control the process by choosing the appropriate laws of time variation of the modulating function and the frequency of the carrier signal.

In recent years, a number of engineering problems in the industry of development of technical systems for creating the pulsed EMFs $[2,5,8]$ have been solved and methods for calculating some types of the pulsed EMF have been proposed as well as an approximate computational scheme for estimating the quasi-static stresses under "magnetic impact" - a particular type of the pulsed electromagnetic 
action [9-13]. The methods for determining the stressed state of current-carrying systems [14], as well as electrically conductive bodies under the influence of steady-state and quasi-steady-state EMFs are known [15]. Various issues of multifaceted problem of describing the influence of the EMFs on continual environment are discussed in [16]. However, the mathematical models and methods for describing the thermally stressed state of electroconductive bodies under the influence of the pulsed EMF with amplitude modulation that are widely used in the practice of electromagnetic processing have not been sufficiently developed in literature.

The article proposes a version of thermomechanics of non-ferromagnetic electroconductive bodies under the influence of the pulsed EMFs with amplitude modulation, taking into account the peculiarities of the effects of the pulsed EMFs on the material continuum to construct rational regimes of pulsed electromagnetic processing and to operate electrically conductive structural elements under such an effect when ensuring their carrying capacity.

\section{Initial assumptions}

Let us consider the pulsed EMF, which are described by the values of the magnetic field strength vector $\boldsymbol{H}(\boldsymbol{r}, t)$ on the surface of a conductive body of the form

$$
\boldsymbol{H}\left(\boldsymbol{r}_{0}, t\right)=\boldsymbol{H}_{0}\left(\boldsymbol{r}_{0}, t\right) \equiv \boldsymbol{H}^{0}\left(\boldsymbol{r}_{0}, t\right) \cos \omega t \quad \text { or } \quad \boldsymbol{H}\left(\boldsymbol{r}_{0}, t\right)=\boldsymbol{H}_{0}\left(\boldsymbol{r}_{0}, t\right) \equiv \boldsymbol{H}^{0}\left(\boldsymbol{r}_{0}, t\right) \sin s \omega t .
$$

Here $\boldsymbol{H}^{0}\left(\boldsymbol{r}_{0}, t\right)=H_{*}(t) \boldsymbol{H}_{0}^{*}\left(\boldsymbol{r}_{0}\right)$ is the modulated amplitude; $\boldsymbol{H}_{0}^{*}\left(\boldsymbol{r}_{0}\right)$ is the amplitude of the carrier signal, $H_{*}(t)$ is the function of the change in time that has pulse nature and describes the time dependence of the signal, which modulate the amplitude of the electromagnetic oscillations (the amplitude of the carrier regime) and satisfies the conditions $H_{*}(t) \leqslant 1 t \in\left[0, t_{i}\right], H_{*}(0)=0, H_{*}\left(t_{i}\right)=0 ; \omega$ is the carrier circular frequency; $t_{i}$ is the time duration of electromagnetic influence; $\boldsymbol{r}$ and $\boldsymbol{r}_{0}$ are the radii-vectors of the points of volume and surface of the electrically conducting body.

We consider the parameters $\boldsymbol{H}_{0}^{*}\left(\boldsymbol{r}_{0}\right), H_{*}(t), \omega, t_{i}$, for which the acting pulsed EMF refers to the class of pulsed "non-destructive" fields with pulse duration of less than a fraction of a second $(t \leqslant 0.1 \mathrm{~s})$ and with the highest magnitude of magnetic field induction that does not exceed $50 \mathrm{~T}\left(B_{\max } \leqslant 50 \mathrm{~T}\right)$. We restrict ourselves to the EMFs, whose action does not give rise to shock waves yet $\left(H_{\max } \leqslant 10^{7} \mathrm{~A} / \mathrm{m}\right.$, where $H_{\max }$ is the largest value of the magnetic field strength on the surface of the body) $[2,5,6,8,17-19]$. We formulate the problems of mathematical physics, which describe thermal and mechanical process under such an electromagnetic effect.

For the above-defined values of stress and strain (the parameters of the electromagnetic action), their velocities of change in the body for the defined parameters are so small that the dependences of the linear theory of elasticity are fulfilled. Thus the influence of the mobility of the environment on the EMF characteristics can be neglected. The process of deformation of an electroconductive body has a dynamic nature, for which the well-known peculiarities of mechanical behavior of the deformable bodies under dynamic and impulsive, as well as force and thermal loads are characteristic (the values of the dynamic modulii of elasticity of metals and their alloys differ little from static ones, and the value $\sigma_{d}$ of the dynamic limit of elastic deformation can increase in $2 \div 3$ times in comparison with the static limit of elastic deformation $\sigma_{s}$ and is determined experimentally for various materials depending on the deformation rate) [20-23].

We consider widespread isotropic homogeneous non-dielectric non-ferromagnetic bodies for which electromechanical and thermoelectric effects are insignificant and the induction vectors $\boldsymbol{D}$ and $\boldsymbol{B}$ are parallel to the vectors of electric $\boldsymbol{E}$ and magnetic $\boldsymbol{H}$ field strengths, and the conduction current $\boldsymbol{j}$ is parallel to $\boldsymbol{E}$. In this case, we assume that the material equations of the electrodynamics have the form $\boldsymbol{D}=\varepsilon \boldsymbol{E}, \boldsymbol{B}=\mu \boldsymbol{H}, \boldsymbol{j}=\sigma_{0} \boldsymbol{E}$, where $\varepsilon=\varepsilon_{0} \varepsilon_{*}, \mu=\mu_{0} \mu_{*} ; \varepsilon_{*}, \mu_{*}$ are the electric and magnetic permeability constants respectively, $\sigma_{0}$ is the electrical conductivity coefficient (values that are determined experimentally or theoretically for specific physical models of solids), $\varepsilon_{0}, \mu_{0}$ are the electric and magnetic constants respectively. 


\section{The calculated physicomathematical model}

Under the accepted assumptions, the influence of the pulsed EMF with amplitude modulation on the processes of heat conduction and deformation in an electroconductive body, as well as for the quasi-steady EMF [15], is taken into account by taking into account the Joule heat dissipation

$$
Q=\sigma_{0} \boldsymbol{E} \cdot \boldsymbol{E}=[\operatorname{rot} \boldsymbol{H}(\boldsymbol{r}, t)]^{2} / \sigma_{0}
$$

and ponderomotive forces

$$
Q=\sigma_{0} \boldsymbol{E} \cdot \boldsymbol{E}=[\operatorname{rot} \boldsymbol{H}(\boldsymbol{r}, t)]^{2} / \sigma_{0} .
$$

These factors lead to the emergence of unsteady temperature and mechanical fields. The ponderomotive moments of forces are equal to zero $\left(\boldsymbol{M}^{*}=\boldsymbol{M}_{E}^{*}+\boldsymbol{M}_{M}^{*}\right.$, where $\boldsymbol{M}_{E}^{*}=\boldsymbol{P} \times \boldsymbol{E}$ are the electric moments, and $\boldsymbol{M}_{M}^{*}=\boldsymbol{M} \times \boldsymbol{B}$ are the magnetic moments; $\boldsymbol{M}_{M}^{*}=\boldsymbol{M} \times \boldsymbol{B}$ and $\boldsymbol{M}=\boldsymbol{B} / \mu_{0}-\boldsymbol{H}$ are the polarization and magnetization vectors respectively) due to the parallelism of the induction vectors and the electric and magnetic field strengths vectors. In this approximation and for constant characteristics of the material (in particular, equal to the average values in the considered temperature range), the initial relations for the quantitative description of the parameters that characterize the electromagnetic, thermal and mechanical processes in the bodies under pulsed electromagnetic action can be formulated in two stages.

At the first stage, based on the general theory of the interaction of the EMF and the electrically conductive continuum [16], we write the equations for determining the parameters of the EMF and expressions for the production of heat and ponderomotive forces as functions of the electromagnetic parameters.

At the second stage, we formulate dependences describing the mechanical and thermal parameters at given initial and boundary conditions for the temperature $T$, and components of the stress tensor $\hat{\sigma}$, in which the Joule heat discharges and ponderomotive forces found at the first stage become the sources of heat and volumetric forces. For the known temperatures and components of the stress tensor $\hat{\sigma}$, we analyze the parameters of the existing physical and mechanical processes and their peculiarities depending on the pulsed electromagnetic loads, and also from the condition $\sigma_{i}=\sqrt{3 I_{2}(\hat{\sigma})-I_{1}^{2}(\hat{\sigma})} / \sqrt{2} \leqslant \sigma_{d}$ (where $\sigma_{i}$ is the stress intensity [20-22]; $I_{j}(\hat{\sigma}), j=1,2$ are the invariants of the stress tensor) we determine the permissible parameters of the pulsed EMF, which provide the limit carrier capacity of the bodies under consideration.

\section{Correlation of a variant of the thermomechanics of conducting bodies under the action of pulsed fields}

The solution of such a complex problem, even for bodies of simple geometric configuration, is associated with significant mathematical difficulties. In order to use approximate methods for solving the constituent tasks (in particular, the thermoelasticity problem at the second stage) we choose $\boldsymbol{H}, T, \hat{\sigma}$ as the key functions and relatively to them we formulate the tasks of mathematical physics. Note that the formulation of the direct problems with respect to these key functions allows us to use effectively the method of polynomial approximation of solutions and significantly improve their accuracy $[18,19]$.

At the first stage, neglecting the displacement currents under the condition of absence of free charges in the body and basing on the Maxwell equations for a non-ferromagnetic electroconductive body, we write the equations for determining the parameters of the EMF (magnetic field strength vector $\boldsymbol{H}$ ),

$$
\Delta \boldsymbol{H}-\sigma_{0} \mu \frac{\partial \boldsymbol{H}}{\partial t}=0, \quad \operatorname{div} \boldsymbol{H}=0,
$$

and appropriate expressions for the heat ejection $Q$ and the ponderomotive forces $\boldsymbol{F}$.

Mathematical Modeling and Computing, Vol. 6, No. 1, pp. 30-36 (2019) 
According to the existing factors of influence of the EMF on the body, the temperature $\boldsymbol{F}$ and the components of the stress tensor $\sigma_{i k}(i, k=\overline{1,3})$ are represented as a sum of two components $T=T^{Q}+T^{F}, \sigma_{i k}=\sigma_{i k}^{Q}+\sigma_{i k}^{F}$, where $T^{Q}, \sigma_{i k}^{Q}$ and $T^{F}, \sigma_{i k}^{F}$ are the components, conditioned by the Joule heat and the ponderomotive forces respectively, $T$ is the temperature deviation from the initial $T_{0}, \mathrm{~K}$.

It is known that for an electromagnetic action of a class of pulsed "non-destructive" EMFs, the bodies during such an action are heated adiabatically - the temperature at a point is determined only by the amount of the EMF energy irreversibly absorbed in the corresponding elementary volume of the body (by the Joule heat) $[6,8,9]$. Under these conditions, the temperature $T^{Q}$ is determined by the dependence

$$
T^{Q}(\boldsymbol{r}, t)=\frac{\varkappa}{\lambda} \int_{0}^{t} Q(\boldsymbol{r}, t) d t
$$

where $\varkappa, \lambda$ are the coefficients of temperature and thermal conductivity.

Assuming that the body is free from force loading, from the equations of thermoelasticity for determining the components $\sigma_{i k}^{Q}$ of the value $\hat{\sigma}^{Q}$ of the stress tensor, caused by the temperature $T^{Q}$, we obtain the system of equations $[15,17,18]$

$$
\operatorname{Def}\left(\operatorname{Div} \hat{\sigma}^{Q}\right)=\rho \frac{\partial^{2}}{\partial t^{2}}\left[\frac{1}{2 G} \hat{\sigma}^{Q}+\left(\alpha T^{Q}-\frac{\nu}{E} \sigma_{*}^{Q}\right) \hat{I}\right]
$$

which is solved under initial $[15,17,18]$

$$
\sigma_{i k}^{Q}(\boldsymbol{r}, 0)=0, \quad \frac{\partial \sigma_{i k}^{Q}(\boldsymbol{r}, 0)}{\partial t}=0, \quad i \neq k ; \quad \frac{\partial \sigma_{i k}^{Q}(\boldsymbol{r}, 0)}{\partial t}=-\frac{\alpha E}{1-2 \nu} \frac{\partial T^{Q}(\boldsymbol{r}, 0)}{\partial t}, \quad i=k
$$

and boundary $\sigma_{i k}^{Q} n_{k}=0$ conditions when $\boldsymbol{r}=\boldsymbol{r}_{0}$. Here: $\sigma_{*} \equiv I_{1}(\hat{\sigma})=\sigma_{k k} ; G=E /[2(1+\nu)]$ is the shearing modulus; $\alpha, \nu$ are the coefficients of linear thermal expansion and Poisson's; $E$ is the Young's modulus; $\delta_{i k}$ is the Kronecker symbol, $\rho$ is the density of the body material; $\hat{I}$ is the unit tensor.

For determining the components of temperature $T^{F}$ and stresses $\sigma_{i k}^{F}$ caused by the action of the ponderomotive force, we take into account that thermal perturbation in an electroconductive body (caused by deformation due to the dynamic force action - the ponderomotive force $\boldsymbol{F}$, which has a pulsed character) is small. Therefore, during the pulsed electromagnetic action, the process of deforming of the electroconductive body can be considered as adiabatic, during which the temperature $T^{F}$ increase is determined by the formula $[17,18,20-22]$

$$
T^{F}=-\frac{\left[\left(3 \lambda_{*}+2 \mu_{*}\right) \alpha \varkappa T_{0} \sigma_{k k}^{F}\right]}{\left[\lambda\left(3 \lambda_{s}+2 \mu_{*}\right)\right]}=-\frac{\alpha \varkappa T_{0}}{\left[1+3 \varepsilon_{*}(1-\nu) /(1+\nu)\right] \lambda} \sigma_{k k}^{F},
$$

where $\varepsilon_{k k}^{F}$ is the first invariant of the deformation tensor $\hat{e}^{F} ; \lambda_{*}, \mu_{*} \equiv G$ are the isothermal coefficients of Liame. In (6) it is taken into account that for the adiabatic deformation of the body, the Hooke's law is determined by the relation

$$
\sigma_{i k}^{F}=2 \mu_{*} \varepsilon_{i k}^{F}+\lambda_{s} \varepsilon_{k k}^{F} g_{i k}
$$

Then $\varepsilon_{k k}^{F}=\sigma_{k k}^{F} /\left(3 \lambda_{s}+2 \mu_{*}\right)$ where $\lambda_{s}=\lambda_{*}+\left[\left(3 \lambda_{*}+2 \mu_{*}\right)^{2} \alpha \varkappa T_{0}\right] / \lambda=\left[\nu E\left(1+\varepsilon_{*}(1-\nu) / \nu\right)\right] /[(1+$ $\nu) \times(1-2 \nu)]$ is the adiabatic Liame coefficient, $\varepsilon_{*}$ is the parameter of connection of deformation and temperature fields. The components of the term $\hat{\sigma}^{F}$ of the stress tensor satisfy the equations

$$
\operatorname{Def}\left(\operatorname{Div} \sigma_{i k}^{F}+\boldsymbol{F}\right)=\rho \frac{\partial^{2}}{\partial t^{2}}\left(\frac{1}{2 G} \sigma_{i k}^{F}-\frac{\nu \nu_{*}}{E} \sigma_{*}^{F} \delta_{i k}\right),
$$

under initial

and boundary

$$
\sigma_{i k}^{F}(\boldsymbol{r}, 0)=0, \quad \frac{\partial \sigma_{i k}^{F}(\boldsymbol{r}, 0)}{\partial t}=0
$$

$$
\sigma_{i k}^{F} n_{k}=0 \quad \text { when } \quad t>0
$$

conditions, where $\nu_{*}=1+\left[(1-\nu)(1-2 \nu) \varepsilon_{*}\right] /\left[\nu(1+\nu) \times\left(1+3 \varepsilon_{*}(1-\nu) /(1+\nu)\right)\right]$. 
Note that if we function on equations (4) and (7) by an incompatibility operator Ink and taking into account that Ink Def $\equiv 0$, as well as the above formulated initial conditions on the stress tensors $\hat{\sigma}^{Q}$ and $\hat{\sigma}^{F}$, we obtain Ink $\hat{e}^{Q}=0$ and Ink $\hat{e}^{F}=0$, i.e. the conditions for the co-existence of deformations are fulfilled identically when the equations (4) and (7) are fulfilled.

\section{Numerical analysis of thermomechanical behavior of the conductive hollow and solid cylinders under the action of electromagnetic pulses}

As an example in Figs. 1-3 we present the results of studies of the thermomechanical behavior of the electroconductive hollow (internal $r_{0}=0.008 \mathrm{~m}$ and external $r_{1}=0.01 \mathrm{~m}$ radii) and solid (radius $R=0.01 \mathrm{~m}$ ) cylinders under the influence of the pulse EMF, which is given by the values of the axial component $H_{z}$ of the magnetic field strength vector on the surface of cylinders in the form

$$
H_{z}\left(r_{0}, t\right)=H_{z}\left(r_{1}, t\right)=H_{z}(R, t)=H_{0} \cdot H_{*}(t)
$$

where $H_{*}(t)=k\left(e^{-\beta_{1} t}-e^{-\beta_{2} t}\right), H_{0}$ are the maximum values of the magnetic field strength, $k$ is the normalizing multiplier; $\beta_{1}, \beta_{2}$ are the parameters that characterize respectively the durations $t_{\text {iner }}$ and $t_{d e c r}$ of the fronts of increasing and decreasing of the pulse.

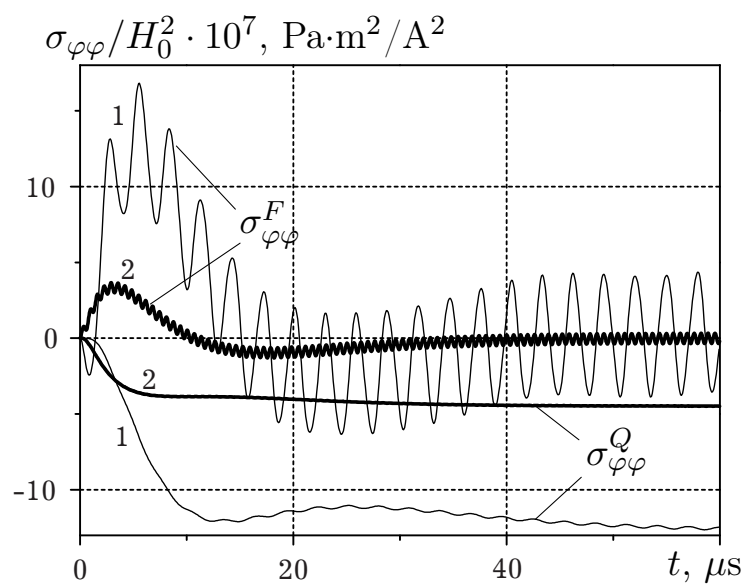

Fig. 1.

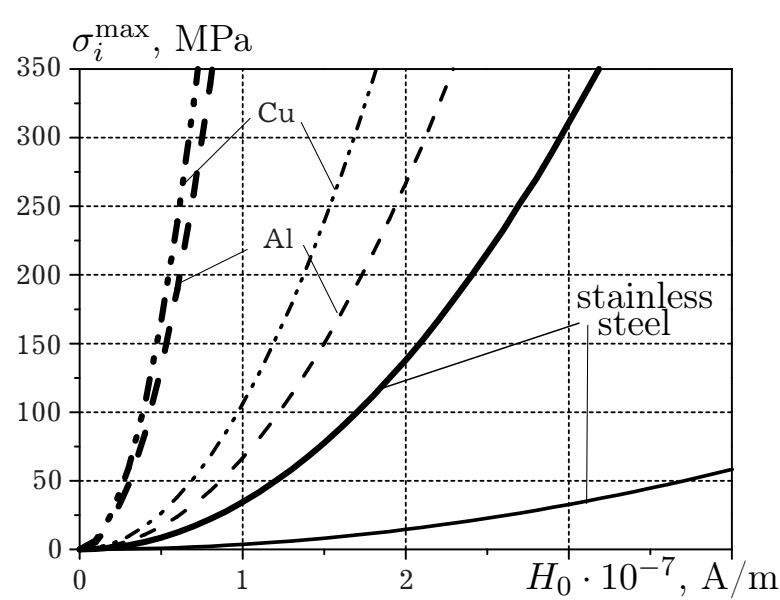

Fig. 3.

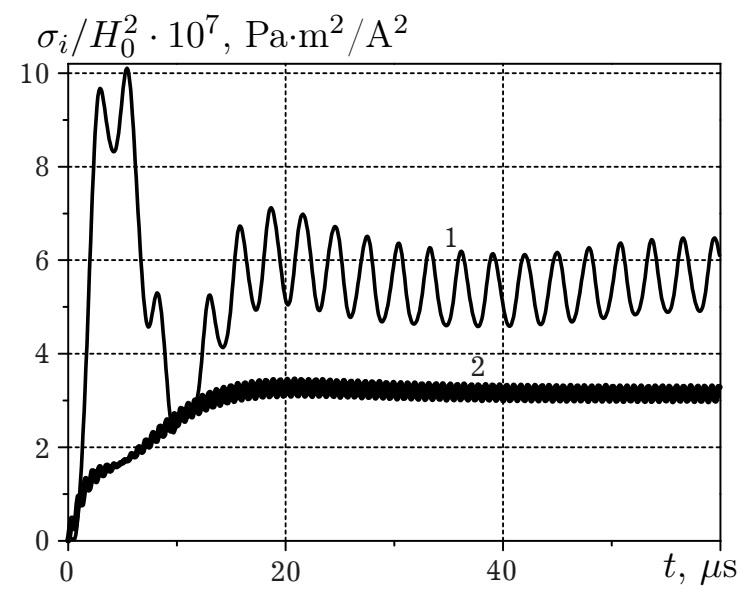

Fig. 2 .

The change in time of circular stresses and intensity of stresses on the outer surfaces of the hollow (line 2) and solid (line 1) cylinders (made of steel $\mathrm{X} 18 \mathrm{H} 9 \mathrm{~T}$ ) are shown in Figs. 1, 2. In both cylinders, the stresses $\sigma_{\varphi \varphi}^{Q}$ are compressible, and the stresses $\sigma_{\varphi \varphi}^{F}$ are stretching at the initial moments of time. In a solid cylinder, the magnitude and nature of the change in time of stress intensity is mainly determined by the ponderomotive force, and in the hollow by the Joule heat.

The Fig. 3 shows the dependence of the maximum values of the total intensity of stresses $\sigma_{i}$ in the hollow cylinders made of stainless steel, copper and aluminum on the value $H_{0}$ at different the EMF durations (the hairlines correspond to $t_{i}=10^{-3} \mathrm{~s}$,

while the thick ones are for $t_{i}=10^{-4} \mathrm{~s}$ ). On the basis of these dependences, the critical values $H_{0}$ are obtained and for them the carrier capacity of the electrically conducting hollow cylinder is preserved. 


\section{Conclusions}

On the basis of relations for the variant of the thermomechanics of electric bodies under the action of the pulsed EMFs, written in the invariant form, one can investigate the thermomechanical behavior and the carrier capacity of non-ferromagnetic electromagnetic bodies of different geometric form under the action of the characteristic types of the pulsed EMF with modulation of amplitude.

The constructed dependences of the maximum values of the stress intensities in the considered conductive bodies of a particular form, depending on the amplitude-time parameters and the pulsed EMF with amplitude modulation, are the theoretical basis for constructing the rational regimes of pulsed electromagnetic processing of electroconductive elements of structures in order to preserve their workability.

[1] Batygin Yu., Lavinsky V., Khimenko L. T. Pulsed Magnetic Fields for Advanced Technologies. Kharkov, BRIDGE Tornado (2003), (in Russian).

[2] Shneerson G. A., Dolotenko M. I., Krivosheev S. I. Strong and Superstrong Pulsed Magnetic Fields Generation. De Gruyter (2010).

[3] Asai S. Electromagnetic Processing of Materials. Springer, Netherlands (2012).

[4] Parkinson A. H., Mullhall B. E. The generation of high magnetic fields. New York, Plenum Press (1967).

[5] Miura N., Herlach F. Pulsed and ultrastrong magnetic fields. In: Herlach F. (eds) Strong and Ultrastrong Magnetic Fields and Their Applications. Top. Appl. Phys. Vol. 57. Springer, Berlin, Heidelberg (1985).

[6] Herlach F. Pulsed Magnets. Rep. Prog. Phys. 62 (6), 859-920 (1999).

[7] Montgomery D. B. Solenoid Magnet Design. Wiley-Interscience (1969).

[8] Knoepfel H. Pulsed High Magnetic Fields. North-Holland Publ. (1970).

[9] Moon F. C. Problems in magneto-solid-mechanics. Mech. Today. 4, 307-390 (1978).

[10] Moon F. C. Mechanics of Superconducting Structures. New York, ASME, AMD vol. 41 (1980).

[11] Moon F. C., ChattopadhyayS. Magnetically Induced Stress Waves in a Conduction Solid - Theory and Experiment. J. Appl. Mech. 41 (3), 641-646 (1974).

[12] Hachkevych O. R., Musii R. S. Temperature fields and stress state of an electrically conductive layer under the magnetic shock on its surfaces. In: Physicomechanical fields in deformable media. Kiev, Naukova Dumka, 28-33 (1978), (in Russian).

[13] Hachkevych O. R., Musii R. S. Temperature fields and thermoelastic state of electrically conductive plates under the magnetic shock. Math. Meth. Phys. Mech. Fields. 7, 115-118 (1978), (in Russian).

[14] Ambartsumian S. A., Bagdasarian G.E., Belubekian M.V. On the magnetoelasticity of thin shells and plates: PMM Vol. 37, N¹, 1973, pp. 114-130. J. Appl. Math. Mech. 37 (1), 102-118 (1973).

[15] Podstrigach Ya. S., Burak Ya. Y., Hachkevych O. R., Chernyavskaya L. V. Thermoelasticity of electrically conductive bodies. Kiev, Naukova Dumka (1977), (in Russian).

[16] Maugin G. A. Continuum Mechanics of Electromagnetic Solids. North-Holland (1988).

[17] Burak Ya. Y., Gachkevich A. R., Musii R. S. Thermoelasticity of conductive solids under the conditions of pulsed electromagnetic fields. Matematychni Metody ta Fizyko-Mekhanichni Polya. 49 (1), 75-84 (2006), (in Ukrainian).

[18] Gachkevich A. R., Musii R. S., Tarlakovsky D. V. Thermomechanics of Non-ferromagnetic Conductive Solids under the Action of Pulsed Electromagnetic Fields with Amplitude Modulation. Lviv, SPOLOM (2011), (in Ukrainian).

[19] Musii R. S. Thermal Stressed State of Conducting Cylinders Subjected to the Electromagnetic Action in the Mode with Pulsed Modulating Signals. Materials Science. 50 (4), 496-506 (2015).

[20] Boley B. A., Weiner J. H. Theory of Thermal Stresses. New York, Wiley (1960).

[21] Kovalenko A. D. Thermoelasticity: Basic Theory and Applications. Wolters-Noordhoff Publ. (1970).

[22] Nowacki W. Dynamic Problems of Thermoelasticity. Springer (1975).

[23] Hetnarski R. B., Eslami M. R. Thermal Stresses - Advanced Theory and Applications. Springer Netherlands (2009). 


\title{
Математичне моделювання в термомеханіці електропровідних тіл під дією імпульсних електромагнітних полів з модуляцією амплітуди
}

\author{
Гачкевич O. ${ }^{1,2}$, Мусій $\mathrm{P}^{3}$ \\ ${ }^{1}$ Інститут прикладних проблем механіки і математики ім. Я. С. Підстригача НАН України, \\ вул. Наукова, 3-б, Лъвів, 79060, Україна \\ ${ }^{2}$ Політехніка Опольська, вул. Прушковська, 76, Ополе, 45-758, Польща \\ ${ }^{3}$ Національний університет "Львівсъка політехніка", \\ вул. С. Бандери, 12, Львів, 79013, Україна
}

У роботі запропоновано математичну модель опису та методику визначення термонапруженого стану неферомагнітних електропровідних тіл під дією зовнішніх нестаціонарних електромагнітних полів імпульсного типу, які мають характер запровадженого в інженерній практиці режиму з модуляцією температури за імпульсного модулівного сигналу. Ця модель $є$ розвитком відомих у літературі моделей для квазістаціонарного та імпульсного електромагнітних полів. Як приклад наведено результати досліджень термомеханічної поведінки суцільного і порожнистого циліндрів за дії на них електромагнітного імпульсу.

Ключові слова: математична модель, термомеханіка, неферомагнітні електропровідні тіла, порожснистий та суцільний циліндри, електромагнітний імпульс.

2000 MSC: $74 \mathrm{H} 10$

удк: 539.3 